\title{
Scaffolding for mathematics teaching in inclusive primary classrooms: a video study
}

\author{
Mirjam Pfister ${ }^{1}$ Elisabeth Moser Opitz ${ }^{1}$ Christine Pauli ${ }^{2}$
}

Accepted: 27 July 2015 / Published online: 8 August 2015

(C) FIZ Karlsruhe 2015

\begin{abstract}
Scaffolding is an important tool for meeting the challenging needs of heterogeneous groups of students in inclusive classrooms. It is especially useful when supporting low achievers. A video study (funded by the Swiss National Science Foundation, Project Nr. 134652) of 36 inclusive classes, (3rd grade, aged 9 years), was conducted to examine how classroom teachers and special education teachers implemented a remedial mathematics program in a classroom setting. The program focused on the following facets of scaffolding: cognitive activation, stimulating discourse, handling errors productively, target orientation, and using manipulatives. The results show that $54 \%$ of the teachers achieved a high competency for using manipulatives and target orientation, facets for which the program provided more detailed instructions. The teachers attained lower values for stimulating discourse, cognitive activation, and handling errors productively, where the program offered more general guidance. The special education teachers had lower rating scores than the classroom teachers, although the same scoring pattern as the teachers. This study shows that it is possible to encourage the use of scaffolding in inclusive classrooms. However, the disparate results for the different facets imply that scaffolding in classroom situations is a competency that cannot simply be adopted from a "program", and more intensive teacher training programs seem to be necessary.
\end{abstract}

Mirjam Pfister

mpfister@ife.uzh.ch

1 Institut für Erziehungswissenschaft, Universität Zürich, Hirschengraben 48, 8001 Zurich, Switzerland

2 Departement Erziehungswissenschaften, Universität Freiburg/Fribourg, Rue Faucigny 2, 1700 Fribourg, Switzerland
Keywords Scaffolding - Low achievers in mathematics . Inclusive classrooms $\cdot$ Video study

\section{Introduction}

Ever since the German speaking countries ratified the United Nations Convention on the Rights of Persons with Disabilities (2006), education policy in those countries has favoured the inclusion of students with special educational needs (SEN) into regular classrooms. This has resulted in challenges for mathematics teachers as they are faced with an increased range of abilities in the classroom and the specific learning requirements of SEN students. Research (e.g. Montague 2011) shows that highly structured and organized programs help teachers to support SEN students. However, remedial programs for low achievers in mathematics are often designed for individual students or small groups rather than for whole-class instruction (Fuchs et al. 2012). Also, the field of mathematics education for low achievers favours explicit, often direct, instruction or schema-based instruction (Rittle-Johnson 2006; Stone 1998), which generally consists of narrow questions, specific directives and "drill and practice" work, such as working on addition and subtraction problems with flash cards or applying a "recipe" to solve problems (e.g. Fuchs et al. 2008). These instructions and practices carry the risk that students learn to follow directions without understanding the process. Thus, it is important to have programs that are structured, and provide guidance while simultaneously taking into account the learners' comprehension. We concur with Stone (1998, p. 361) that the "metaphor of scaffolding" is useful for supporting low achievers in mathematics. Scaffolding is a form of support that is both comprehension orientated and structured (cf. Sect. 2.2). 
In this paper, we first give an overview of the current state of knowledge on high quality instruction for low achievers in mathematics. We then develop a concept of scaffolding using aspects we feel are essential for supporting low achievers in mathematics. Finally, we describe a remedial program for inclusive classroom settings created using knowledge on mathematics instruction for low achievers and our concept of scaffolding. The program was implemented in 36 inclusive classrooms, and we assessed the implementation of the program by two groups of teachers in an exploratory video study, where one group received in-service training and the other group did not.

\section{Research overview}

\subsection{High-quality mathematics instruction for low achievers}

In this article we use the term low achievers for students whose mathematics performance ranges from lower than average to well below average. These students are often referred to as having mathematical learning difficulties or mathematical disabilities. Although there are issues with establishing the diagnostic criteria for distinguishing these categories (Murphy et al. 2007), there are empirical studies that characterise low achievers' mathematical competence and describe the specific difficulties low achievers experience in mathematics. These students often have difficulties in specific arithmetic areas such as conceptual understanding, such as the decimal place value system and problem solving (Mazzocco et al. 2008), and procedural competencies, such as counting or memorizing number facts (Andersson 2010).

So what specific type of instruction is best suited to help low achievers? Intervention studies (e.g. Pedrotty Bryant et al. 2008; Freesemann 2014; Wißmann et al. 2013; Woodward and Brown 2006) show that it is important to focus on understanding certain mathematical topics, including a conceptual understanding of number concepts (e.g. base-ten number system, place value, and the meaning of operations) and selected procedural competencies (e.g. addition and subtraction problems, and fluency in basic facts like adding up to 100 and counting by groups).

Research has also identified successful teaching strategies. In a review paper, Montague (2011) concludes that highly structured and organized programs, which use procedures such as cueing, modelling, verbal rehearsal, and feedback, benefit low achievers in mathematics (see also Heward 2003; Jones and Brownell 2014). These aspects of effective instruction are further elucidated in a metaanalysis by Gersten et al. (2009). The authors highlight the following teaching strategies as being fruitful for these students: Teaching heuristics to solve word problems, giving students explicit instructions, using visual representations and manipulatives, thoughtful selection and sequencing of instructional examples, and encouraging students to verbalize their own strategies or strategies modelled by the teacher.

In addition, effective instructions for low achievers are highly dependent on successful interactions between students and teachers (Hammond and Gibbons 2005). This discourse is a crucial tool in helping students to acquire mathematical knowledge (Williams and Baxter 1996). Guided discourse enables the sharing and discussion of mathematical ideas between the teacher and his/her students and between the students. This provides the opportunity to review and reorganise students' knowledge (Alexander 2008). The teacher plays a central role in this process: $\mathrm{He}$ or she has to guide this discourse by asking purposeful questions and encouraging students to share their ideas and strategies with others.

Although research has identified the important factors in teaching low achievers mathematics, the challenge remains for teachers to adapt their teaching to suit the needs of individual learners (Corno and Snow 1986). This is particularly demanding in inclusive classrooms. Therefore it is important to investigate suitable tools and strategies. The concept of scaffolding provides tools for achieving the goals discussed above.

\subsection{Scaffolding}

The idea of scaffolding originates from Wood et al. (1976). Scaffolding is described as "... processes that enable the child or novice to solve a problem, or carry out a task or achieve a goal which would be beyond his unassisted efforts" (Wood et al. 1976, p. 90). The tutor interprets the learning behaviour and makes decisions about which stimulating tasks to use, whether and when to intervene and support, and how much and what type of help is necessary (Wood 2001). Van de Pol et al. (2010) highlights contingency, fading, and transfer of responsibility as key components of scaffolding. They describe the following scaffolding means by which the learning activities of a student can be supported:

- Feeding back: providing information regarding the student's performance

- Giving hints: providing clues or suggestions

- Instruction: what to do or how something must be done and why

- Explaining: providing more detailed information or clarification

- Modelling: offering behaviour for imitation 
- Questioning: questions that require an active linguistic and cognitive answer

Hammond and Gibbons (2005) identify two levels at which scaffolding can be applied: macro-scaffolding which includes planning, goal setting, classroom organisation, and the selection and sequencing of tasks, and micro-scaffolding, which is contingent interaction in response to the teaching and learning opportunities.

Scaffolding is a method of adapting teaching to the individual needs of students in the classroom. It has, however, been characterized in many different ways by various authors. Below, we discuss selected aspects of scaffolding which are closely correlated with high quality instructions for low achievers in mathematics (cf. Sect. 2.1). We categorise our choices as "facets" of scaffolding, and these facets are later used to analyse the implementation of scaffolding in inclusive classrooms. The five facets of scaffolding are described and listed below:

Cognitive activation: Krammer (2009) and van de Pol et al. (2010) concur that cognitive activation is an important goal of scaffolding. According to Stone (1998, p. 353), "in a scaffolding situation, the child is led to participate in an activity whose full meaning has yet to be fulfilled. That is, the child is acting in anticipation of full understanding and must develop an understanding from the actions in which he or she is led to engage". Thus, scaffolding enables the students' (meta-)cognitive activation (van de Pol et al. 2010), which is crucial for constructing conceptual understanding (cf. Sect. 2.1). Cognitive activation also includes fading and transfer of responsibility. The more the students participate, the more the responsibility for the learning process will be transferred to them. An essential tool for cognitive activation is the teacher's restatements or summaries of what has been done or said in class (Williams and Baxter 1996), and the emphasis is on asking questions, rather than giving directions (Lepper et al. 1997).

Stimulating discourse: Interactions between the teacher and the students and between the students are important in order to achieve cognitive activation (Krammer 2009). Williams and Baxter (1996) present scaffolding as a core element of discourse-orientated learning "...to describe actions taken by a teacher that support the creation of mathematical knowledge through discourse among students" (p. 22). Therefore, stimulation discourse in classrooms is critical.

Handling errors productively: The starting-point of a discourse between the teacher and the students is often a misconception or an error. According to a study by Lepper et al. (1997), the best tutors seem to respond to student errors differently than their less effective colleagues. The authors emphasize that teachers have to know helpful "techniques" to tackle the errors and misconceptions (e.g. debug errors by posing leading questions or offering hints to prompt students to identify and correct the errors by themselves).

Target orientation: Scaffolding always involves the careful selection of the learning materials and appropriate tasks or mathematics problems (Applebee and Langer 1983; Krammer 2009; Lepper et al. 1997). The teacher has to use appropriate questions, instructions, and explanations to draw students' attention to selected instructional examples, and thus to key concepts or "mathematical ideas" (Williams and Baxter 1996).

Using Manipulatives: In mathematics instruction, the way problems are presented is especially important. The teacher has to decide how to present a problem to the students, and to decide on suitable examples, manipulatives, and representations (Lepper et al. 1997). Low achievers in mathematics, in particular, require the active representation of facts through the use of manipulatives in order to understand problems (cf. Sect. 2.1).

The concept of scaffolding was originally developed for the use in one-to-one tutorial situations; however, it is now also applied to classroom situations (Smit et al. 2013). Therefore, it is important to understand how to encourage classroom teachers to use scaffolding and how to train them to use the various techniques in scaffolding. Lepper et al. (1997) discuss some types of training (i.e. peer-tutoring programs and computer tutors). On the basis of Lipowsky's (2004) results, we decide that in-service training in scaffolding techniques would be an effective option.

\section{Research questions}

Using the five facets of scaffolding identified in our scaffolding concept, we developed a remedial program (cf. Sect. 4.3). We investigated the program's implementation in inclusive classrooms in grade 3. The study aimed to answer the following questions:

- How does the use of scaffolding manifest itself in mathematics lessons in inclusive classrooms in grade 3 ?

- What level of competence do classroom teachers and special education teachers show in using scaffolding strategies in their teaching practice?

In order to gather information about the kind of framework required to implement such a program, we evaluated the impact of in-service training on teachers' use of scaffolding in the classrooms. It was assumed that an in-service training event related to instructional practice would have a positive impact on the implementation of the program (Lipowsky 2004). This then led to the following question: 
- What is the impact of the in-service training on the implementation of scaffolding?

\section{Methods}

\subsection{Design and sample}

Our study investigates scaffolding in complex classroom situations. This leads to challenges for establishing an assessment strategy (van de Pol et al. 2010). We use a video study in our investigation because as Praetorius (2014) reports, rating videotaped classrooms is an important method to assess teaching quality. Video analysis allows for the detailed investigation of the structures and processes of teaching.

The video data (cross-sectional data) were gathered as a part of a longitudinal study on the impact of mathematics interventions. The preliminary results of the longitudinal study are reported elsewhere (Pfister et al. 2015).

To answer the research questions, we use two different approaches. First, we analyse the use of scaffolding in the classrooms on the basis of the five facets we have identified (cognitive activation, stimulating discourse, handling errors productively, target orientation, and using manipulatives) to determine the level of success in the implementation of scaffolding. Second, to describe the characteristics of the levels and to elucidate differences in how scaffolding is implemented, we conduct a case study with three teachers.

The sample consists of 36 inclusive elementary school classes (3rd graders) from 28 schools in the Germanspeaking part of Switzerland. The teachers volunteered to participate after being approached via a letter of invitation. According to the teachers and a mathematics test that was conducted in the framework of the aforementioned longitudinal study (Pfister et al. 2015), all classes include low achievers in mathematics.

In some of the classes, extra help from a special education teacher (SET) was available. SETs should have additional training in special education and be particularly qualified to support low achieving students and therefore, would be expected to be better versed in using scaffolding (Nougaret et al. 2005). However, due to a scarcity of qualified specialists, teachers without special education training often work as SETs. Unfortunately, it was not possible to gather data on the professional background of the SETs in our study. A further complication is that the level of support provided by SETs was inconsistent and depended on local or cantonal regulations. Therefore, the inclusive classes that we examined varied in terms of composition, available support, and lessons and type of collaboration of the teachers.

\subsection{Intervention}

At the beginning of the school year, we held a three hour session with the teachers and the SETs, where we introduced the program and provided our intervention materials (lesson plans, worksheets, Dienes blocks etc.). The teachers then implemented the program over the course of the next 6 months. Using the lesson plans provided, the teachers prepared mathematics lessons on the themes of the decimal place value system, number lines, and addition/subtraction. In order to gather information on the influence of in-service training, the teachers were randomly assigned to two groups (Table 1). Half of the teachers (group ${ }^{\text {Meet }}$ ) took part in an in-service training session twice ( $3 \mathrm{~h}$ each) during this period. During these training sessions, teachers were given additional help with implementing the lesson plans and were trained, with the help of examples of best-practise, to identify opportunities for using scaffolding. Based on the results of Lipowsky (2004), we expected a higher level of scaffolding for group ${ }^{\text {Meet }}$.

The second group (group ${ }^{\text {Mat }}$ ) only attended the program introductory session and received the support material. The teachers were able to decide to what extend they adhered to our lesson plans, and we asked them to fill out and submit bi-monthly protocol sheets detailing their use of the lesson plans and support material. One mathematics lesson was videotaped in order to monitor how the program was implemented. A final phone interview was also conducted to ask teachers how often and how much they used the material. Teachers who didn't use the program regularly were excluded from the sample.

\subsection{Remedial program}

The remedial program was designed based on our concept of scaffolding and what is known about high quality instruction for low achievers. It also drew on the results of one of our earlier studies (Freesemann 2014, cf. section 2.1). In that study, a highly structured program for low achieving 5th graders had a significant impact on mathematics achievement. In this study, the intervention for 3 rd graders pursues the following objectives (for a full concept of the intervention, see Stöckli et al. 2014):

Table 1 Intervention groups and the numbers of teachers and students in each group

\begin{tabular}{|c|c|c|c|}
\hline \multicolumn{2}{|c|}{ Teachers $(\mathrm{N}=36)$} & \multicolumn{2}{|c|}{ Students $(\mathrm{N}=511)$} \\
\hline Group $^{\text {Meet }}$ & Group $^{\text {Mat }}$ & Group $^{\text {Meet }}$ & Group $^{\text {Mat }}$ \\
\hline 20 & 16 & 255 & 256 \\
\hline
\end{tabular}


- Development of conceptual understanding, particularly of the decimal place value system (Mazzocco et al. 2008)

- Understanding of basic operations (Moser Opitz 2013)

- Thoughtful selection and sequencing of instructional examples: Suggestions for teachers on how to focus on key concepts and their central core content elements (Williams and Baxter 1996; Applebee and Langer 1983; Krammer 2009; Lepper et al. 1997).

- Targeted use of graphical representations and manipulatives (Gersten et al. 2009, Lepper et al. 1997, e.g. Dienes blocks for grouping and de-grouping, empty number lines for addition and subtraction problems).

- Stimulating classroom discourse (Williams and Baxter 1996; Alexander 2008).

- Use of scaffolding tools: Pre-formulated questions and hints for different phases of instruction (e.g. giving hints, questioning, modelling, explaining) (van de Pol et al. 2010).

The "centrepiece" of the program consists of three modules on the themes of the decimal place value system, the number line, and addition/subtraction. Each module contains several lesson plans (30 lessons in total). The individual lesson plans supplement or replace textbook pages, or are carried out prior to working from the textbook. They contain suggestions on the differentiation for different levels of competence with corresponding thought, action and observation assignments and manipulatives. Each lesson contains an introduction, a work phase (group, partner or individual work) and an extensive reflection phase. These lessons aim to encourage students to present and explain their mathematical ideas and notions, to compare other ideas with their own, and to discuss them with others.

In the lesson plans, scaffolding means are formulated as concrete verbal impulses, shown in Table 2.

\subsection{Video analysis}

This study examines the use of scaffolding in the context of classroom instruction. Of interest in the following is whether the teachers were successful in implementing the program and in particular the scaffolding impulses.

Three to five months after the start of the intervention, one mathematics lesson was videotaped in each class. The teachers were asked to initiate, from a freely chosen lesson plan, an introductory or reflection sequence with the whole class and an individual work phase. They were able to choose whether to carry out the lesson on their own or with the special education teacher (SET); they were merely told to conduct the mathematics lesson using the remedial program in the same manner as they had been doing it over the previous couple of weeks. In order to ensure that we recorded "natural classroom interactions", we accepted a
Table 2 Scaffolding impulses

\begin{tabular}{|c|c|}
\hline Facet & Scaffolding impulses \\
\hline Cognitive activation & $\begin{array}{c}\text { Compare! What do you notice? What } \\
\text { did you have to do so that ...? }\end{array}$ \\
\hline Stimulating discourse & $\begin{array}{l}\text { Describe what you have done! Can } \\
\text { you explain that in more detail? Are } \\
\text { there any other ways how we can } \\
\text { solve it? Can we write/calculate it } \\
\text { differently? }\end{array}$ \\
\hline Handling errors productively & $\begin{array}{l}\text { Where are you stuck? What are you } \\
\text { considering? How did you find it } \\
\text { out? How can we find out whether } \\
\text { that's correct? }\end{array}$ \\
\hline Target orientation & $\begin{array}{l}\text { Describe the rule/pattern! Why does it } \\
\text { have to be done like that? }\end{array}$ \\
\hline Using manipulatives & $\begin{array}{l}\text { Can you show that with manipula- } \\
\text { tives? Can we place/do it differ- } \\
\text { ently? }\end{array}$ \\
\hline
\end{tabular}

reduced level of standardisation. To address the complex context of classroom instruction, all mathematics lessons were videotaped using the two-camera principle: one dynamic camera for recording the interaction-relevant context of the mathematics instruction and one static camera for the whole class. In lessons in which a SET was also present, the class camera was used for the SET once the SET was interacting with students. This could also mean that the recordings with the second camera took place in a different room.

Two of the 36 video recordings had to be excluded from the analyses as the teachers had not adhered to the requirements for the recordings. Therefore, the analyses were conducted on 34 mathematics lessons. In 19 of the analysed videos, the teacher was teaching alone. In 15 classes, the teacher and the SET worked together as a team or the class was divided into two groups, one with the teacher and the other with the SET. Due to technical problems with the recordings, we could only analyse 12 of the 15 SET-videos.

\subsection{High-inference rating to describe the use of scaffolding}

A high-inference rating system was developed to analyse the videotaped lessons (Table 3). The rating system uses the five facets of scaffolding to provide high quality instructions for low achievers in mathematics (cf. Sect. 2.1). These facets are: Cognitive activation, stimulating discourse, handling errors productively, target orientation, and using manipulatives. Scaffolding means (cf. Sect. 2.2) are included in all of the facets. The rating system serves to qualitatively assess the extent to which the teachers implement scaffolding, and provides a way to characterise whole-class instructions ("classroom discourse") and 
Table 3 High-inference rating system

\begin{tabular}{|c|c|c|}
\hline Facets & Indicators & IR \\
\hline & The teacher & \\
\hline \multirow[t]{2}{*}{ Cognitive activation } & $\begin{array}{l}\text { Poses clear, content-related, meaningful, challenging questions } \\
\text { and problems, provides stimulation for describing or substanti- } \\
\text { ating facts, observations, etc. }\end{array}$ & $.83(.93)$ \\
\hline & Enables the establishment of relationships between contents & \\
\hline \multirow[t]{3}{*}{ Stimulating discourse } & $\begin{array}{l}\text { Invites the students to comment on contributions or actions of } \\
\text { others }\end{array}$ & $.85(.93)$ \\
\hline & Responds to students' contributions & \\
\hline & Initiates reflections on solution strategies & \\
\hline \multirow[t]{5}{*}{ Handling errors productively } & Recognises the learning potential or difficulty of a situation & $.63(.71)$ \\
\hline & Intervenes in the learning processes in a supportive manner & \\
\hline & $\begin{array}{l}\text { Endeavours to understand the students' solution strategies or } \\
\text { reflections }\end{array}$ & \\
\hline & Supports students in tackling problems independently & \\
\hline & Checks the students' understanding following the intervention & \\
\hline \multirow[t]{3}{*}{ Target orientation } & Focuses on core content elements & $.77(.84)$ \\
\hline & Demonstrates what is important, points out conventions & \\
\hline & $\begin{array}{l}\text { Summarises important findings, recapitulates these findings in } \\
\text { his/her own words }\end{array}$ & \\
\hline \multirow[t]{3}{*}{ Using manipulatives } & Employs manipulatives to support the learning process & $.76(.90)$ \\
\hline & Allows facts to be represented actively using manipulatives & \\
\hline & $\begin{array}{l}\text { Emphasises the understanding of structure or the systematic use } \\
\text { of the manipulatives }\end{array}$ & \\
\hline
\end{tabular}

$I R$ inter-rater reliability Kendall's tau b, teacher (special education teacher) individual student work phases to compare the lessons in terms of these facets. These facets are operationalized using indicators (Table 3 ).

Our rating manual describes an ideal performance for every facet. The facets are rated on a four-point scale. The ratings describe an overall judgement that is based on the frequency or proportion of time taken by a behaviour, the intensity or degree of the shown behaviour (how many of the indicators apply), and the distribution of the behaviour within the class (Rakoczy and Pauli 2006). Thus, a 4 signifies full compliance with the ideal performance, a 3 signifies a rather good compliance, a 2 means a little compliance, and a 1 means no compliance with the ideal performance. Five videos were discursively rated by the whole rating team to serve as reference ratings. Two people rated each video individually. If there were disagreements following the independent rating, a consensus rating was reached.

The inter-rater reliability corresponds to the requirements (Table 3). In an exploratory factor analysis (Table 4), all facets load onto one factor (loadings between .88 and 93, Cronbach's alpha .94.), which means that the facets are components of one scaffolding scale.

Each teacher (and SET) was assigned a general level of competence in using scaffolding, across all facets by applying the criteria listed below. We did not use a mathematical
Table 4 Summary of items and factor loadings for varimax orthogonal one-factor solution for the concept of scaffolding

\begin{tabular}{ll}
\hline & Factor loading \\
\hline Item & 1 \\
Cognitive activation & .93 \\
Stimulating discourse & .91 \\
Handling errors productively & .90 \\
Target orientation & .90 \\
Using manipulatives & .88 \\
\hline
\end{tabular}

Cronbach's alpha: .94

average, as the same rank can exhibit different profiles, particularly in the middle ranges. The levels were:

- Low-Minimal use of scaffolding: Scores of 1 and 2 across all five facets; no more than one 3.

- Medium-Good use of scaffolding: Either scores of 2 and 3 across all five facets, or the scores span at least three rating levels.

- High-Accomplished use of scaffolding: Scores of 3 and 4 across all five facets; no more than one 2.

Particularly within the medium group, the use of scaffolding within the same rank can exhibit very different 
profiles based on whether predominantly medium scores (e.g. 23323 ) or high and low scores (e.g. 1244 2) were achieved.

In order to be able to glean practical information about the impact of specific interventions, such as in-service and pre-service training, and in order to identify successful scaffolding strategies, it was also important to investigate the impacts of individual facets. Therefore, we also analysed the rating scores separately for each facet.

\section{Results}

First, we provide an overview of the rating results of the whole sample. These show that despite the detailed lesson plans and identical support materials, there are large differences in how the teachers used scaffolding in the classrooms. To illustrate these differences, we then present three case studies with different rating results.

\subsection{Rating scores overall}

Table 5 shows that over half of the teachers in both experimental groups achieved high rankings for using scaffolding.

Only $14.7 \%$ of teachers showed a low level of scaffolding use. As we compare the two groups, it becomes apparent that there are somewhat fewer teachers with a high level of scaffolding use in group ${ }^{\text {Meet }}$ than in group ${ }^{\text {Mat }}$, although in the former group there is only one teacher in the lowest level. Among the teachers, a $\chi^{2}$ test $\left(\chi^{2}[2]=5.59 ; p=.06\right.$; Cramers $\mathrm{V}=.41$ ) indicates a tendency towards a difference in favour of group ${ }^{\text {Meet }}$. The special education teachers' (SET) scores are distributed equally across the three levels of scaffolding use, with one third achieving each level.

Table 6 shows the teachers' scores in every facet of scaffolding.

Cognitive activation: $27 \%$ achieved the highest score, $33 \%$ the second highest, $24 \%$ the second lowest and $15 \%$ earned the lowest score. The teachers in group ${ }^{\text {Mat }}$ appeared to be somewhat more successful than the teachers in group $^{\text {Meet }}$.

Stimulating discourse: Just under $25 \%$ in each case achieved scores 3 and 4, $33 \%$ scored 2, and $18 \%$ scored 1 . Here too, differences between the groups can be discerned, with over half of the teachers in group ${ }^{\text {Meet }}$ showing rather low scores and over half of the teachers in the group ${ }^{\text {Mat }}$ showing high scores.

Handling errors productively: $61 \%$ of teachers achieved high scores, around $40 \%$ earned low scores, and once again, high scores can be detected somewhat more frequently in group ${ }^{\text {Meet }}$.

Target orientation: The teachers showed a high level of competency in target orientation (almost $60 \%$ with the
Table 5 Number of teachers according to the level of use of scaffolding

\begin{tabular}{llll}
\hline & \multicolumn{3}{l}{ Level of use of scaffolding } \\
\cline { 2 - 4 } & Low & Medium & High \\
& $\mathrm{n}(\%)$ & $\mathrm{n}(\%)$ & $\mathrm{n}(\%)$ \\
\hline Teacher total $(\mathrm{N}=34)$ & $5(14.7)$ & $11(32.4)$ & $18(53.9)$ \\
Group $^{\text {Meet }}(\mathrm{n}=20)$ & $1(5)$ & $9(45)$ & $10(50)$ \\
Group $^{\text {Mat }}(\mathrm{n}=14)$ & $4(28.6)$ & $2(14.3)$ & $8(57.1)$ \\
SET total $^{(\mathrm{n}=12)}$ & $4(33.3)$ & $4(33.3)$ & $4(33.3)$ \\
SET Group $^{\text {Meet }}(\mathrm{n}=5)$ & $3(60)$ & 0 & $2(40)$ \\
SET Group $^{\text {Mat }}(\mathrm{n}=7)$ & $2(28.6)$ & $3(42.9)$ & $2(28.6)$ \\
\hline
\end{tabular}

Table 6 Number of teachers according to assessment on the facets of scaffolding

\begin{tabular}{|c|c|c|c|c|c|}
\hline \multirow[t]{2}{*}{ Facet } & \multirow[t]{2}{*}{ Group } & \multicolumn{4}{|c|}{ Rating, $N=34$} \\
\hline & & 1 & 2 & 3 & 4 \\
\hline \multirow{3}{*}{$\begin{array}{l}\text { Cognitive acti- } \\
\text { vation }\end{array}$} & & $5(15.2)^{\mathrm{a}}$ & $8(24.2)$ & $11(33.3)$ & $9(27.3)$ \\
\hline & Group $^{\text {Meet }}$ & 1 & 7 & 7 & 4 \\
\hline & Group $^{\text {Mat }}$ & 4 & 1 & 4 & 5 \\
\hline \multirow{3}{*}{$\begin{array}{c}\text { Stimulating } \\
\text { discourse }\end{array}$} & & $6(18.2)$ & $11(33.3)$ & $8(24.2)$ & $8(24.2)$ \\
\hline & Group $^{\text {Meet }}$ & 2 & 9 & 4 & 4 \\
\hline & Group $^{\text {Mat }}$ & 4 & 2 & 4 & 4 \\
\hline \multirow{3}{*}{$\begin{array}{l}\text { Handling errors } \\
\text { productively }\end{array}$} & & $7(21.2)$ & $6(18.2)$ & $10(30.3)$ & $10(30.3)$ \\
\hline & Group $^{\text {Meet }}$ & 2 & 5 & 8 & 5 \\
\hline & Group $^{\text {Mat }}$ & 5 & 1 & 2 & 5 \\
\hline \multirow{3}{*}{$\begin{array}{l}\text { Target orienta- } \\
\text { tion }\end{array}$} & & $3(9.1)$ & $7(21.2)$ & $4(12.1)$ & 19 (57.6) \\
\hline & Group $^{\text {Meet }}$ & 0 & 5 & 2 & 12 \\
\hline & Group $^{\text {Mat }}$ & 3 & 2 & 2 & 7 \\
\hline \multirow{3}{*}{$\begin{array}{l}\text { Using manipula- } \\
\text { tives }\end{array}$} & & $2(5.9)$ & $5(14.7)$ & 7 (20.6) & $20(58.8)$ \\
\hline & Group $^{\text {Meet }}$ & 1 & 1 & 5 & 13 \\
\hline & Group $^{\text {Mat }}$ & 1 & 4 & 2 & 7 \\
\hline
\end{tabular}

a Number of teachers (percentage). Due to reasons pertaining to instruction and recording, it was not possible to rate all facets for some teachers

highest score, $12 \%$ with the second highest score). A third, however, earned low scores. High scores can be detected somewhat more frequently in group ${ }^{\text {Meet }}$.

Using manipulatives: The teachers achieved the highest scores in the use of manipulatives. $59 \%$ of the teachers achieved the highest score; $21 \%$ achieved a score of 3 and only $6 \%$ had a score of 1 . In group ${ }^{\text {Meet }}$, most of the teachers achieved the two highest scores; in groupMat, high and low scores are achieved with roughly equal frequency. 
Table 7 Scaffolding impulses from the lesson plan 'informal addition strategies'

\begin{tabular}{ll}
\hline Core/focus & Scaffolding impulses \\
\hline Structured use of the blocks & Can you see right away how many units it has? \\
& Can you see at a glance what the number is? \\
& Can you place the blocks in such a way that you don't have \\
to count? & At what place value does something change? \\
Changes in place values & What changes? \\
Comparing different solution strategies & How did you calculate this problem? \\
& Who else calculated the problem like child X? \\
& Who chose a different solution strategy? \\
Logging stepwise on the empty number line & Write down all solution steps \\
& First calculate up to the next hundred \\
& Try to find a way that is as handy as possible \\
Reflecting empty number line logs & What was child X thinking about with this empty number \\
& line? \\
& Where did a mistake occur with this empty number line?
\end{tabular}

In summary, the following pattern emerges when analysing the teachers: A high rating is most frequently scored in the facets using manipulatives and target orientation; high scores are less frequent for cognitive activation, stimulating discourse and handling errors productively. Overall, the ratings in group ${ }^{\text {Meet }}$ are somewhat better than those in group $^{\text {Mat }}$, except for the facets cognitive activation and stimulating discourse.

As the SET sample is very small, these results need to be interpreted with caution. Only a small number of particularly noteworthy findings will be reported. As the SETs participated in the instruction in very different ways, it was not possible to rate all facets. For example, if a SET was only accompanying individual students during the individual work phase, stimulating discourse could not be rated. Essentially, the picture resembles that of the teachers. The SETs achieved the highest rating scores most frequently in the facets target orientation and using manipulatives. However-in contrast to the teacher ratings-the SETs scored the lowest ratings on several occasions. This is also apparent for the other facets: Low scores emerged more frequently among the SETs than among the teachers.

\subsection{Differences in the use of scaffolding: three case studies}

Below, three case studies will be presented to highlight the nuances between the different levels of the use of scaffolding. The cases were selected to be as comparable as possible with respect to class size (16 to 21 children per class) and the selected instructional theme, but they differ in terms of the overall rating of the teachers (one teacher of each level). All of the lessons described here were developed using the lesson plan 'informal addition strategies' from the module 'informal addition and subtraction strategies' (cf. Sect. 4.3). To contextualise the presented cases, the objective and the content of the lesson plan are briefly described:

- Preliminary exercises on grouping and de-grouping (with the use of cue cards with arithmetic problems with operative relationship such as $268+5,268+50$, $268+500$ or $400-100,400-10,400-1)$

- Trying out and discussing the different informal strategies (stepwise and place values extra)

- Use Dienes blocks in addition and subtraction problems

- Logging strategies (place values extra: $374+555 \rightarrow 3$ $00+500+70+50+4+5=800+120+9=920$ $+9=929$; stepwise: $374+555 \rightarrow 374+500 \rightarrow 874$ $+50 \rightarrow 924+5=929$ ) as well as the stepwise notation on the empty number line

Important elements emphasised in the lesson plan are the structured use of the blocks, comparing and recording solution strategies, and discussing changes in place values. Scaffolding impulses (cf. Table 2) are formulated in a theme-specific manner (Table 7).

The following case studies describe how the three teachers, Peter, Tom and Eva, carried out this lesson plan and how adaptively they proceeded. We examine to what extent the rating differences are manifested in the performances.

Cognitive activation: In contrast to Eva, Peter and Tom showed only a limited degree of success regarding students' cognitive activation (Table 8).

Peter did not call for any descriptions of observations or explanations and substantiations of reflections or actions, carried out all activities himself, and posed narrow questions, as the following transcript illustrates [P1-P2]: 
Table 8 Comparison facet: cognitive activation

\begin{tabular}{|c|c|c|}
\hline \multicolumn{3}{|l|}{ Cognitive activation } \\
\hline Peter $(1)^{\mathrm{a}}$ & Tom (2) & Eva (4) \\
\hline $\begin{array}{l}\text { Set tasks with small steps } \\
\text { Told the students which actions } \\
\text { they have to carry out } \\
\text { Posed questions which require a } \\
\text { one-number answer } \\
\text { Carried out actions with the } \\
\text { manipulatives himself }\end{array}$ & $\begin{array}{l}\text { Carried out actions with the manipulatives himself } \\
\text { Often told students solution steps } \\
\text { Sometimes requested observation, description, } \\
\text { or substantiation of facts and findings } \\
\text { Sometimes requested comparison of solution } \\
\text { strategies }\end{array}$ & $\begin{array}{l}\text { Constantly requested students to verbalise and } \\
\text { substantiate their solution steps } \\
\text { Allowed problems (even correctly solved ones) to } \\
\text { be discussed } \\
\text { Invited the formulation of insights and observa- } \\
\text { tions }\end{array}$ \\
\hline
\end{tabular}

a $\quad()=$ Individual score for this facet

Table 9 Comparison facet: stimulating discourse

\begin{tabular}{|c|c|c|}
\hline \\
\hline Peter (1) & \multicolumn{2}{|c|}{$\begin{array}{l}\text { Stimulating discourse } \\
\text { Peter (1) }\end{array}$} \\
\hline Asked for numbers, results & Formulated central findings himself & Asked for reflections \\
\hline $\begin{array}{l}\text { Let the students finish sentences he } \\
\text { has started }\end{array}$ & $\begin{array}{l}\text { Primarily asked for results or subsequent steps } \\
\text { Let the students finish sentences he has started }\end{array}$ & $\begin{array}{l}\text { Let thought processes and insights to } \\
\text { be presented }\end{array}$ \\
\hline Spoke most of the time & $\begin{array}{l}\text { Sometimes let the students "dictate" the next steps } \\
\text { In isolated cases, he incorporated contributions from the } \\
\text { children into the class discussion }\end{array}$ & $\begin{array}{l}\text { Interrupted the students' contribu- } \\
\text { tions }\end{array}$ \\
\hline
\end{tabular}

Teacher Peter [P]: Stepwise addition $387+235$ on the blackboard (09:43-10:27)

P1: So, we take the first number, three hundred and eighty seven. And two hundred $[387+200=$ is already on the blackboard under the calculation $387+235$, $\mathrm{P}$ points to the written numbers]. How much does that make?

Linus: Five hundred and eighty seven.

P2: [writes number on the board after $387+200=$ ]

Exactly. Now I have this five hundred and eighty seven [writes 587 under $387+200$ ], I'll write it under it. So, I've added the hundreds to it, now come the tens. Now I add thirty [writes 30]. How much does that make?

Demir: Six hundred and seventeen.

In the class, students primarily watched how sample problems were solved. Accordingly, the cognitive challenges posed by Peter's impulses were low, and the students' contributions were limited to providing answers to simple computations. Tom conducted his class in a similar manner. On occasions, however, Tom got the students to participate by encouraging them to describe and substantiate their observations and solutions. Eva, by contrast, constantly invited the students to observe, compare and substantiate their conclusions. The students therefore received continuous cognitive stimuli and participated in their progress throughout the lesson.

Stimulating discourse: A similar pattern is also apparent regarding stimulating discourse, although Eva did not achieve the highest score here (Table 9).
Eva managed to stimulate discourse well. She asked the students questions that usually required an elaborate answer. She constantly invited the students to speak, but at times left little space for more detailed descriptions and interrupted the children's contributions. Peter did not request any verbalisation of the students' reflections; the students primarily had to provide the results of the prompted arithmetic steps. Thus, it is not possible to reflect on his use of solution strategies, because the students did not enter into conversation about the "matter at hand", and students only communicated by providing answers prompted by the teacher. In Tom's class too, there was little exchange between the students. He also formulated many work steps himself and did not give the students a chance to describe their insights. However, he did sometimes ask the students to comment on their strategies and results.

Handling errors productively: Eva acted in a highly adaptive manner when she used scaffolding means to handle errors, while Tom and Peter achieved a low score in this facet (Table 10).

Eva endeavoured to understand, reproduce and "diagnose" the students' procedures and the sources of their errors by asking the students to verbalise their procedures. She also let errors or problems to be explicitly named, meaning that they can be actively tackled. Peter's support behaviour consisted of giving the students the next step when they made mistakes or are uncertain [P3-P6], or writing the steps down directly in the students' exercise books himself. In contrast to Eva, he did not give students 
Table 10 Comparison facet: handling errors productively

\begin{tabular}{|c|c|c|}
\hline \multicolumn{3}{|l|}{ Handling errors productively } \\
\hline Peter (1) & Tom (2) & Eva (4) \\
\hline $\begin{array}{l}\text { Demanded that certain procedures } \\
\text { to be carried out }\end{array}$ & $\begin{array}{l}\text { Provided hints for using the structure of the } \\
\text { Dienes blocks }\end{array}$ & $\begin{array}{l}\text { Requested verbalisation of the procedure } \\
\text { Requested substantiation and proof }\end{array}$ \\
\hline $\begin{array}{l}\text { When students were uncertain, he } \\
\text { told them how to continue }\end{array}$ & $\begin{array}{l}\text { Requested the students to try the problem } \\
\text { again with help of the manipulatives }\end{array}$ & Provided feedback on systematic procedures \\
\hline $\begin{array}{l}\text { Rubbed out mistakes and wrote } \\
\text { down the solution himself }\end{array}$ & $\begin{array}{l}\text { Demanded more careful work (not specifi- } \\
\text { cally mathematical) }\end{array}$ & $\begin{array}{l}\text { or the mistake to be "named" } \\
\text { Es }\end{array}$ \\
\hline $\begin{array}{l}\text { Pointed to what was written on the } \\
\text { blackboard }\end{array}$ & & problems that have not yet been solved \\
\hline
\end{tabular}

Table 11 Comparison facet: target orientation

\begin{tabular}{lll}
\hline Target orientation & & \\
\hline Peter (1) & Tom (4) & Eva (4) \\
\hline Focused on carrying out the procedure correctly & $\begin{array}{l}\text { Formulated central findings } \\
\text { Always pointed out important things } \\
\text { Recapitulated insights or relevant things }\end{array}$ & $\begin{array}{l}\text { Summarised the students' thoughts } \\
\text { "Translated" student contributions } \\
\text { Worked out key characteristics and proce- } \\
\text { dures }\end{array}$ \\
& &
\end{tabular}

the opportunity to describe their reflections or to verbalise their efforts at solving the problem.

Teacher Peter: Solving stepwise addition in the exercise book (20:12-20:33)

Sofija: Do I now have to (this one here)?//P: No//[indecipherable because $\mathrm{P}$ interrupts] (on the board) [points to and looks at the blackboard]//

P3: [interrupts] Look, now, hey, hey [Sofija looks in the exercise book]. You mustn't do that, you're not ready yet, now it's the six hundred and [indecipherable].

Sofija: [interrupts, indecipherable] I//

P4: Now you have to take this number [points in the exercise book]

Sofija: just have to, those ones one down there [points to number in the exercise book] write them under each other, then I have to//

P5: [at the same time] calculate those too

Sofija: So calculate and then comes//

P6: [interrupts] and then comes the next one.

In this way, the students were not actively included in the solution process and thus were unable to recognise and correct incorrect thought processes.

Tom also made little effort to track down the source of students' errors. However, he did try to solve the problem together with the students and tried to support the students. He did this primarily by giving hints, asking the students to repeat the problem with the aid of manipulatives, and instructing them to work carefully. Nevertheless, he did not give any task-related supportive hints and did not refer to core content elements.

Target orientation: With regard to target orientation, Eva and Tom achieved the highest rating, and Peter the lowest (Table 11).

The high goal orientation in Eva and Tom's instruction is clear in the way that they repeatedly emphasized key processes of understanding by using scaffolding means such as summarising, translating or recapitulating findings. In this way, the students' thoughts were constantly steered to the "crux of the matter". Eva, in particular, engaged students to "think arithmetically" during the individual work phase (math problems with operative relationship that focus on place changes) and supported the students in formulating findings. Peter, by contrast, primarily focused on the procedural aspect and not on the process of understanding. His lack of target orientation for his students manifested itself through their failure to recognise that the notation of the solution strategies is a protocol or the visualisation of an (thought) action with the Dienes blocks.

Using manipulatives: All three teachers employed manipulatives and representations, but only Tom and Eva used these explicitly to stimulate learning processes through scaffolding (Table 12).

Tom emphasised that there were different ways of using the Dienes blocks, but he only expressed this verbally and did not manage to implement it in practice with the students. Eva, for her part, focused on the characteristics of certain forms of notations and worked these out clearly [E1-E4]. Thus, she fostered both the understanding and the appropriate use of 
different forms of notations in individual solution processes through leading questions and reframing:

Teacher Eva: Reflections on the empty number line (01:26-2:33)

Lina: So this is an empty number line, so still not//E: Yes?//yet. But//

E1: Why not yet?

Lina: Because//E: But it's a nice line?

Lina: Yes, but there's no arrow in this direction and then [E holds out the chalk to Lina, she goes to the blackboard]. So, here, you have to [draws arrow towards the right and 1000 at the right end of the line]//

E2: [interrupts] There's something missing there. And where else is something missing? [E hands Tim another piece of chalk].

Tim: A zero here [writes arrow to the left and 0 at the left end of the line].

E3: Good, and now we know that it's an empty number line, because it already has arrows on it. Why isn't it a number line now? We know about the number line too. Why do you say now that it's an empty number line?

Sandy: Because a number line starts somewhere and stops somewhere.

E4: Exactly, you have to say exactly and it also has little lines in between [runs her finger along the empty number line and taps on it], so you know exactly where the number is, but here with our empty number line we just do it roughly.

Although Peter employed manipulatives, representations and notation forms, the students themselves barely used the Dienes blocks. Moreover, Peter did not pay attention to the structured use of the Dienes blocks (they lie in a "small heap" and were not placed according to the positional notation). Therefore, the use of Dienes blocks did not help students to find a solution strategy. The students primarily watched the teacher's actions or carried out what the teacher told them, and the structure of the manipulatives was not addressed and worked out. Peter might be 'using manipulatives', but he was not successful in using them as a tool to represent and discuss mathematical problems.

\section{Discussion}

This study examines how teachers in inclusive classrooms executed a remedial program that is based on the concept of scaffolding. We define scaffolding for the special needs of low achievers in mathematics as a concept with five facets: cognitive activation, stimulating discourse, handling errors productively, target orientation, and using manipulatives (cf. Sect. 2.2). 
More than half of the teachers-with slight differences between the group $^{\text {Mat }}$ and group ${ }^{\text {Meet_ }}$-showed a high level of competency in using scaffolding, but there are important differences between teachers. While a particularly large number of teachers showed very high levels of competency in using manipulatives and target orientation, ratings were often lower in the stimulating discourse and cognitive activation facets. These results are remarkable as the work by van de Pol et al. (2010) shows that scaffolding is scarcely used in classrooms. It should be noted that by and large, the teachers in our study followed the lesson plans, which explicitly included support for contingent teaching (e.g. pre-formulated questions and hints for dealing with errors and misconceptions). Therefore, the high usage of scaffolding and the rating differences between the individual facets might also be attributed to the material provided and the guidelines for the remedial program. On the level of macro-scaffolding (Hammond and Gibbons 2005), there are concrete suggestions on using manipulatives and target orientation in the lesson plans. This means that the teachers not only received a great deal of guidance in this respect, but also that the program was largely implemented in terms of these two facets. However, in order to be able to judge the teachers' overall teaching practices with regard to these facets, information would have to be available on whether teachers implemented these practices when they were not provided with lesson plans. Nevertheless, the solid implementation of the suggestions on using manipulatives and target orientation is promising, and it appears to be possible to introduce macro-scaffolding in classroom practice through the use of directed programs.

In the program, there were also suggestions about implementing stimulating discourse and cognitive activation. However, these require micro-scaffolding (Hammond and Gibbons 2005) and therefore a higher level of individual competency from the teachers. For example, following an input initially provided by the teacher (e.g. question: "What do you notice?"), the discourse has to be continued without further aids and the teacher has to react in a contextual fashion. Therefore, conducting a mathematical discussion and implementing discourse-orientated learning (Williams and Baxter 1996) are highly demanding and cannot only be imparted with written documents such as lesson plans. It would be interesting to investigate the effectiveness of peer-tutoring programs to develop teacher competency in these areas (Lepper et al. 1997).

The same applies to handling errors productively. Here, the scaffolding means suggested by the program were rather indirect (e.g. using the question, "How can we find out whether something is correct?" to suggest there is an error). These micro-scaffolding competencies cannot simply be adopted from a "program"; rather, their development requires more intensive training in the sense of longer-term coaching (Beck et al. 2008; Campbell and Malkus 2014; Williams and Baxter 1996).

Teachers in the group ${ }^{\text {Meet }}$ attended two additional in-service training sessions and displayed a slightly higher level of competence in these facets. However, the somewhat higher rating scores of group $^{\text {Mat }}$ in these two facets also point to the importance of individual competencies which were already present before the intervention: Although the suggestions on cognitive activation and discourse in the program were not very explicit, over half of the teachers in this group acted in a highly adaptive manner, and one can suspect that they already possessed these competencies prior to the implementation of the program.

By presenting three case studies, it was possible to describe and to operationalize three types of scaffolding use on the basis of the five facets: a low level of scaffolding use in all areas, a very high level of scaffolding use in all areas, and a mixed form of scaffolding use, in which a teacher's scores on the facets varied. This indicates that the individual competencies of the three teachers also differ greatly, independently of the program.

Overall, the special education teachers (SETs) showed lower rating scores than the classroom teachers, although the same scoring pattern is apparent in terms of the individual facets. The rating differences between the teachers and the SETs need to be interpreted with caution. The SETs were only individually rated if they taught independently of the teacher. Depending on the instructional setting, it was therefore impossible to evaluate all of the parameters. Despite this limitation, the findings raise some questions. As highlighted in Sect. 4.1, the SETs should show particularly high teaching competencies (Jones and Brownell 2014) and therefore be highly skilled in providing adaptive support for low achievers. In this respect, further investigations, which particularly take into account variables such as the training and work experience of the SETs, are necessary.

Therefore, the question of whether these meetings indeed had an effect, and whether the intervention led to the observed teaching practices, can only be answered in the context of a longitudinal study where a baseline of scaffolding competency has been established.

A further area of interest is whether different levels of scaffolding use have an impact on students' learning progress. Lepper et al. (1997) report a significant relationship between a teacher's competency in scaffolding and students' progress. However, this question is not within the scope of this paper. A preliminary analysis of the case study data indicate a significant difference in the mathematics achievement between Peter and Tom's students and those of Eva, the teacher with the highest level of competency in scaffolding.

Finally, some limitations of the study should be pointed out. First, there are the limitations posed by aspects of the design. 
Due to the small sample size, the rating differences between the teachers of the two groups need to be interpreted with caution. Moreover, on the basis of the investigations by Praetorius (2014), one can ask whether it is permissible to undertake an evaluation of cognitive activation using only one video recording. A further difficulty is that the videotaped mathematics lessons are only comparable to a limited degree due to the different themes addressed in the lessons and, particularly, due to the variation in the basic conditions of the classrooms. This is particularly apparent in the lessons that involved two teachers, and led to challenges in the ratings (Pfister et al. 2015). Some of these limitations could be addressed by adapting the design (e.g. a higher standardisation of videotaping, and videotaping several lessons per class). However, other aspects-e.g. the teacher's commitment, the differences in the make-up of the class-will always be a part of the studies carried out under "natural conditions".

Second, there are limitations that result from our theoretical conceptualisation of the study. Our results refer to our working definition of scaffolding. Different criteria might lead to different results. In addition, our concept of scaffolding only incorporates fading and transfer of responsibility (cf. Sect. 2.2)-two important factors of scaffolding - to a limited extent, within the facets handling errors productively and cognitive activation.

\section{Conclusions}

Our study aim to use an exploratory video study to investigate the way scaffolding, which contributes greatly to teaching quality, manifests itself in inclusive classrooms in primary schools. We successfully operationalized the concept of scaffolding with a reliable high-inference rating system that includes the facets cognitive activation, stimulating discourse, handling errors productively, target orientation, and using manipulatives. Our results show that-taking into account the limitations mentioned above- the investigation successfully described the implementation of scaffolding in inclusive classroom instruction. We also demonstrate that the teachers were especially successful at applying macro-scaffolding strategies (using manipulatives, target orientation) from our program. The results for the other facets, which involve micro-scaffolding, show that scaffolding is a competence that cannot simply be adopted from a "program"; it requires more intensive training in some skills. In practical terms, it would be relatively cost efficient to implement programs based on target orientation and using manipulatives. This could be taken into account when developing teaching materials.

There are some major challenges for any future studies. The observation and recording of teaching quality in a setting with two teachers in an inclusive classroom, so-called "nested instruction" (Jones and Brownell 2014, p. 113), makes it difficult to draw conclusions. In addition, our study did not investigate how scaffolding practices develop. Therefore, further investigations should be conducted to examine these teacher competencies from a longitudinal perspective, also considering scaffolding competency both before and after an intervention, and in a "natural" context without the provision of detailed lesson plans by investigators.

Acknowledgments We thank the Swiss National Science Foundation for funding the research. We would like to thank our former students Pia Kessler and Noemi Lüscher for their great help with the video rating.

\section{References}

Alexander, R. (2008). Towards dialogic teaching. Rethinking classroom talk (4th ed.). Cambridge: Dialogos.

Andersson, U. (2010). Skill development in different components of arithmetic and basic cognitive functions: Findings from a 3-year longitudinal study of children with different types of learning disabilities. Journal of Educational Psychology, 102(1), 115-134.

Applebee, A. N., \& Langer, J. A. (1983). Instructional scaffolding: Reading and writing as natural language activities. Language Arts, 60(2), 168-175.

Beck, E., Baer, M., Guldimann, T., Bischoff, S., Brühwiler, C., Müller, P., \& Vogt, F. (2008). Adaptive Lehrkompetenz: Analyse und Struktur, Veränderbarkeit und Wirkung handlungssteuernden Lehrerwissens [Adaptive teaching competence: Analysis and structure, changeability and effects of guiding teacher competence]. Münster: Waxmann.

Campbell, P. F., \& Malkus, N. N. (2014). The mathematical knowledge and beliefs of elementary mathematics specialist-coaches. ZDM - The International Journal on Mathematics Education, 46(2), 213-225.

Corno, L., \& Snow, R. E. (1986). Adapting teaching to individual differences among learners. In M. C. Wittrock (Ed.), Handbook of research on teaching (3rd ed., pp. 605-629). New York: Macmillan.

Freesemann, O. (2014). Schwache Rechnerinnen und Rechner fördern. Eine Interventionsstudie an Haupt-, Gesamt- und Förderschulen [Fostering students with learning difficulties in mathematics. An intervention study in middleschool]. Wiesbaden: Springer Spektrum.

Fuchs, L. S., Fuchs, D., \& Compton, D. L. (2012). The early prevention of mathematics difficulty: Its power and limitations. Journal of Learning Disabilities, 45(3), 257-269.

Fuchs, L. S., Powell, S. R., Hamlett, C. L., Fuchs, D., Cirino, P. T., \& Fletcher, J. M. (2008). Remediating computational deficits at third grade: A randomized field trial. Journal of Research on Educational Effectiveness, 1(1), 2-32.

Gersten, R., Chard, D. J., Jayanthi, M., Baker, S. K., Morphy, O., \& Flojo, J. (2009). Mathematics instruction for students with learning disabilities: A meta-analysis of instructional components. Review of Educational Research, 79, 1202-1242.

Hammond, J., \& Gibbons, P. (2005). Putting scaffolding to work: The contribution of scaffolding in articulating ESL education. Prospect, 20(1), 6-30.

Heward, W. L. (2003). Ten faulty notions about teaching and learning that hinder the effectiveness of special education. The Journal of Special Education, 36(4), 186-205. 
Jones, N. D., \& Brownell, M. T. (2014). Examining the use of classroom observations in the evaluation of special education teachers. Assessment for Effective Intervention, 39(2), 112-124.

Krammer, K. (2009). Individuelle Lernunterstützung in Schülerarbeitsphasen. Eine videobasierte Analyse des Unterstützungsverhaltens von Lehrpersonen im Mathematikunterricht [Teachers' assistance of individual students in mathematics lessons: A video-based study]. Münster: Waxmann.

Lepper, M. R., Drake, M. F., \& O’Donnell-Johnson, T. (1997). Scaffolding techniques of expert human tutors. In K. Hogan \& M. Pressley (Eds.), Scaffolding student learning. Instructional approaches and issues (pp. 108-144). Cambridge: Brookline Books.

Lipowsky, F. (2004). Was macht Fortbildungen für Lehrkräfte erfolgreich? Befunde und mögliche Konsequenzen für die Praxis [What makes an in-service training successful for the teachers? Findings and possible implications for practice]. Die Deutsche Schule, 96, 462-479.

Mazzocco, M. M. M., Devlin, K. T., \& McKenney, S. J. (2008). Is it a fact? Timed arithmetic performance of children with mathematical learning disabilities (MLD) varies as a function of how MLD is defined. Developmental Neuropsychology, 33(3), 318-344.

Montague, M. (2011). Effective instruction in mathematics for students with learning difficulties. In C. Wyatt-Smith, J. Elkins \& S. Gunn (Eds.), Multiple perspectives on diffculties in learning literacy and numeracy (pp. 295-313). doi:10.1007/978-1-4020-8864-3_14.

Moser Opitz, E. (2013). Rechenschwäche-Dyskalkulie: Theoretische Klärungen und empirische Studien an betroffenen Schülerinnen und Schülern [Learning disabilities in mathematics: Theoretical foundations and empirical studies] (2nd ed.). Bern: Haupt.

Murphy, M. M., Mazzocco, M. M., Hanich, L. B., \& Early, M. C. (2007). Cognitive characteristics of children with mathematics learning disability (MLD) vary as a function of the cutoff criterion used to define MLD. Journal of Learning Disabilities, $40(5), 458-478$.

Nougaret, A. A., Scruggs, T. E., \& Mastropieri, M. A. (2005). Does teacher education produce better special education teachers? Exceptional Children, 71(3), 217-229.

Pedrotty Bryant, D., Bryant, B. R., Gersten, R., Scammacca, N., \& Chavez, M. M. (2008). Mathematics intervention for first- and second-grade students with mathematics difficulties: The effects of Tier 2 intervention delivered as booster lessons. Remedial and Special Education, 29(1), 20-32.

Pfister, M., Stöckli, M., Moser Opitz, E., \& Pauli, C. (2015). Inklusiven Mathematikunterricht erforschen: Herausforderungen und erste Ergebnisse aus einer Längsschnittstudie [Investigating mathematics teaching in inclusive classrooms: Challenges and first results of a longitudinal study]. Unterrichtswissenschaft, 43(1), 53-67.
Praetorius, A.-K. (2014). Messung von Unterrichtsqualität durch Ratings [Measuring teaching quality by ratings]. Münster: Waxmann.

Rakoczy, K., \& Pauli, C. (2006). Hoch inferentes Rating: Beurteilung der Qualität unterrichtlicher Prozesse [High-inference rating: Evaluating the quality of teaching processes]. In I. Hugener, C. Pauli, \& K. Reusser (Eds.), Videoanalysen [Video analysis] (Vol. 15, pp. 206-233). Frankfurt am Main: DIPF.

Rittle-Johnson, B. (2006). Promoting transfer: Effects of self-explanation and direct instruction. Child Development, 77(1), 1-15.

Smit, J., van Eerde, H. A. A., \& Bakker, A. (2013). A conceptualisation of whole-class scaffolding. British Educational Research Journal, 39(5), 817-834.

Stöckli, M., Moser Opitz, E., Pfister, M., \& Reusser, L. (2014). Gezielt fördern, differenzieren und trotzdem gemeinsam lernen - Überlegungen zum inklusiven Mathematik-unterricht [Remediation, differentiation and learning together - Reflections on inclusive mathematics teaching]. Sonderpädagogische Förderung heute, 59(1), 44-56.

Stone, C. A. (1998). The metaphor of scaffolding: Its utility for the field of learning disabilities. Journal of Learning Disabilities, $31(4), 344-364$.

United Nations (2006). Convention on the rights of persons with disabilities. Accessed 10 Nov 2014. http://www.un.org/esa/socdev/ enable/rights/convtexte.htm.

van de Pol, J., Volman, M., \& Beishuizen, J. (2010). Scaffolding in teacher-student interaction: A decade of research. Educational Psychological Review, 22, 271-296.

Williams, S. R., \& Baxter, J. A. (1996). Dilemmas of discourse-oriented teaching in one middle school mathematics classroom. The Elementary School Journal, 97(1), 21-38.

Wißmann, J., Heine, A., Handl, P., \& Jacobs, A. M. (2013). Förderung von Kindern mit isolierter Rechenschwäche und kombinierter Rechen- und Leseschwäche: Evaluation eines numerischen Förderprogramms für Grundschüler [Fostering students with mathematical disease and combined mathematical and reading disease: Evaluation of a numeric remedial program in primary schools]. Lernen und Lernstörungen, 2(2), 91-109.

Wood, D. (2001). Scaffolding, contingent tutoring and computer-supported learning. International Journal of Artificial Intelligence in Education, 12, 280-292.

Wood, D., Bruner, J. S., \& Ross, G. (1976). The role of tutoring in problem solving. Journal of Child Psychology and Psychiatry, $17,89-100$

Woodward, J., \& Brown, C. (2006). Meeting the curricular needs of academically low-achieving students in middle grade mathematics. Journal of Child Psychology and Psychiatry, 17, 89-100. 